\title{
PREVALENCE OF HYPERTENSION, OBESITY AND ANEMIA AMONG FIRST YEAR DENTAL STUDENTS IN BAREILLY
}

\author{
Qazi Rais Ahmed1, Rajesh Kumar Seth², Syed Esam Mahmood ${ }^{3}$
}

\section{HOW TO CITE THIS ARTICLE:}

Qazi Rais Ahmed, Rajesh Kumar Seth, Syed Esam Mahmood. "Prevalence of Hypertension, Obesity and Anemia among First Year Dental Students in Bareilly". journal of Evolution of Medical and Dental Sciences 2014; Vol. 3, Issue 44, September 15; Page: 10881-10885, DOI: 10.14260/jemds/2014/3420

ABSTRACT: BACKGROUND \& OBJECTIVES: Hypertension, obesity and nutritional anemia is highly prevalent and largely undiagnosed among dental students. Early identification of these diseases is essential among them, considering their role as future surgeons and role models in public health intervention. Prevalence of hypertension, obesity and anemia among the dental students of Bareilly was studied. METHODS: This cross sectional study was carried out among the first year students of Institute of Dental Sciences, Bareilly after obtaining institutional ethical committee clearance and informed consent of respondents. A structured and pretested questionnaire was used to collect information about the respondent's demographic profile, family history of hypertension and diabetes, the measurement of blood pressure, anthropometrical parameters and anemia. RESULTS: Out of the 107 respondents, nearly $28.0 \%$ had a positive family history of hypertension and/or diabetes. The prevalence of hypertension was $27.1 \%$ while about $28.0 \%$ were found to be overweight. Nearly $57.6 \%$ had an increased waist hip ratio and about $14.8 \%$ were anemic. A higher proportion of males were found to be overweight and hypertensive as compared to the females, the difference being statistically insignificant. Increased waist hip ratio was found to be significantly higher among the males while anemia was significantly higher among the females $(\mathrm{p}<0.05)$. CONCLUSION: Early identification of hypertension, obesity and anemia and their modification among dental students is required.

KEYWORDS: Prevalence, hypertension, obesity, anemia, dental students.

INTRODUCTION: According to a WHO report from 2005, non-communicable diseases (NCDs), accounted for 53\% of all deaths and $44 \%$ of Disability Adjusted Life Years in India. There exists a number of risk factors for NCDs such as high blood pressure, high serum cholesterol, inadequate intake of fruits and vegetables, excess weight, physical inactivity, and alcohol and tobacco use. It has been projected that in the next 10 years, India would be losing an estimated $\$ 237$ billion in the national income as a result of NCDs due to reduced economic productivity. ${ }^{1}$ Adolescence is a significant period of growth and maturation, unique changes occur and many adult patterns are established during this period. ${ }^{2}$ Students joining dental colleges represent this group. Obesity, hypertension and anemia is highly prevalent and largely undiagnosed among dental and medical students.3, 4, 5 Early identification of these diseases is essential among them, considering their role as future surgeons and role models in public health intervention. The present study is an endeavor to study the health status of dental students joining the Dental College. The literature on health status of dental students was scarce; thereby the present study was undertaken to find out prevalence of hypertension, obesity and anemia among the students of Institute of Dental Sciences, Bareilly, Uttar Pradesh, India. 
MATERIAL AND METHODS: This three months (January -March 2012) cross sectional study was carried out among the first year dental students of Institute of Dental Sciences, Bareilly, Uttar Pradesh, India. The approval for this study was obtained from the institutional ethical committee and the consent of all the students was taken. All the first year dental students who were present in the lecture theatre were surveyed and they comprised the study unit. A total of 107 students participated in the study. A structured, self-administered and pretested questionnaire was used to collect information about the respondent's demographic profile, family history of hypertension and diabetes, the measurement of blood pressure and anthropometrical parameters and anemia. The measurements were taken by the authors themselves. The students were assured confidentiality of their responses. Following Operational Definitions were put to use in the present study: Hypertension (using JNC 7 criteria) - mean systolic BP $\geq 140 \mathrm{mmHg}$ and/or mean diastolic BP $\geq 90 \mathrm{~mm}$ $\mathrm{Hg}$ or history of anti-hypertensive treatment fifteen days before the survey.

For physical examination, standardized calibrated mercury column type sphygmomanometer; stethoscope, common weighing machine and measuring tape were used. During the course of the interview, two measurements of blood pressure on each study participant with a mercury column sphygmomanometer were made using a standardized technique 30 minutes apart in sitting position. ${ }^{6}$ Body weight was measured (to the nearest $0.5 \mathrm{~kg}$ ) with the subject standing motionless on the weighing scale, feet about $15 \mathrm{~cm}$ apart and weight equally distributed on each leg. Subjects were instructed to wear minimum outwear (as culturally appropriate) and no footwear while there weight was being measured. Height was measured (to the nearest $0.5 \mathrm{~cm}$ ) with the subject standing in an erect position against a vertical surface, and the head positioned so that the top of the external auditory meatus was level with the inferior margin of the bony orbit (Frankfurt's plain). Body Mass Index was calculated as weight in kilograms divided by weight in meters squared. The cutoff value for normal BMI for men and women was $23 \mathrm{~kg} / \mathrm{m}^{2} .^{7}$

Waist circumference was measured with a standard measuring tape, while subjects were lightly clothed, at a level midway between the lower margin of the last rib and iliac crest in centimeters (to the nearest $0.1 \mathrm{~cm}$ ). Waist circumference (WC) cut-offs were taken as $90 \mathrm{cms}$ for males and $80 \mathrm{cms}$ for females to define abdominal obesity using South Asia Pacific Guidelines. ${ }^{8}$ Hip circumference (HC) was measured at the maximum circumference over the buttocks in centimeters (to the nearest $0.1 \mathrm{~cm}$ ) with the subject in standing position. Waist hip ratio was calculated as waist circumference divided by hip circumference. The cut-off used for the waist-hip ratio (WHR) for males was 0.9 and for females it was 0.8 to define obesity 9 . The haemoglobin estimation was performed by Sahli's haemoglobin meter and results interpreted as per the WHO criteria. Anaemia was established if the haemoglobin was below the cut-off points as recommended by WHO 10,11.

Data entry and statistical analysis were performed using the Microsoft Excel and SPSS windows version 14.0 software. The test of significance (Pearson's Chi-square test) was applied to find out the results. The $p$ values which were $<0.05$ were considered as significant.

RESULT: Out of the 107 respondents, 51.4\% were females. Majority of the respondents (96.3\%) were aged below 20 years and were Hindus (74.8\%). Nearly $28.0 \%$ had a positive family history of hypertension and/or diabetes. (Table 1) The prevalence of hypertension was $27.1 \%$. About $28.0 \%$ were found to be overweight. Nearly $57.6 \%$ had an increased waist hip ratio. About $14.8 \%$ were anemic. A higher proportion of males were found to be overweight and hypertensive as compared to 
the females, the difference being statistically insignificant. Increased waist hip ratio was found to be significantly higher among the males while anemia was significantly higher among the females $(\mathrm{p}<0.05)$. (Table2)

\begin{tabular}{|c|c|}
\hline \multirow{2}{*}{ Characteristics } & Total (n=107) \\
\cline { 2 - 2 } Mender & No. (\%) \\
\hline Female & $52(48.6 \%)$ \\
\hline Age group (years) & $55(51.4 \%)$ \\
\hline 20 and above & $104(96.3 \%)$ \\
\hline Heligion & $3(3.7 \%)$ \\
\hline Muslims & $80(74.8 \%)$ \\
\hline Sikhs & $19(17.8 \%)$ \\
\hline Christians & $6(5.6 \%)$ \\
\hline $\begin{array}{c}\text { Positive family history of } \\
\text { hypertension and/or diabetes }\end{array}$ & $2(1.9 \%)$ \\
\hline Present & $30(28.0 \%)$ \\
\hline Absent & $77(72.0 \%)$ \\
\hline
\end{tabular}

Table 1: Distribution of respondents according to demographic characteristics and family history of hypertension and diabetes

\begin{tabular}{|c|c|c|c|c|}
\hline \multirow{2}{*}{ Risk factors } & Males & Females & Total & \multirow{2}{*}{ p-value } \\
\hline & No. (\%) & No. (\%) & No. (\%) & \\
\hline \multicolumn{5}{|l|}{ Hypertension $(n=107)$} \\
\hline Present & $16(15.0 \%)$ & $13(12.1 \%)$ & $29(27.1 \%)$ & \multirow{2}{*}{$>0.05$} \\
\hline Absent & $36(33.6 \%)$ & $42(39.3 \%)$ & $78(72.9 \%)$ & \\
\hline \multicolumn{5}{|c|}{ Body mass index $(n=107)$} \\
\hline Normal & $36(33.6 \%)$ & $41(38.3 \%)$ & $77(72.0 \%)$ & \multirow{2}{*}{$>0.05$} \\
\hline Increased & $16(15.0 \%)$ & $14(13.1 \%)$ & $30(28.0 \%)$ & \\
\hline \multicolumn{5}{|c|}{ Waist Hip ratio $(n=92)$} \\
\hline Normal & $13(14.1 \%)$ & $26(28.3 \%)$ & $39(42.4 \%)$ & \multirow{2}{*}{$<0.05$} \\
\hline Increased & $31(33.7 \%)$ & $22(23.9 \%)$ & $53(57.6 \%)$ & \\
\hline \multicolumn{5}{|l|}{ Anaemia $(n=61)$} \\
\hline Present & $1(1.6 \%)$ & $8(13.1 \%)$ & $9(14.8 \%)$ & \multirow{2}{*}{$<0.05$} \\
\hline Absent & $25(41.0 \%)$ & $27(44.3 \%)$ & $52(85.2 \%)$ & \\
\hline
\end{tabular}

Table 2: Gender wise distribution of respondents according to modifiable risk factors 
DISCUSSION: Out of the 107 respondents nearly one fourth had a positive family history of hypertension and/or diabetes in this study. In a previous study by Mahmood et al carried among medical students of Barielly, nearly $30.3 \%$ of students had a family history of hypertension while $41.4 \%$ had a family history of diabetes ${ }^{12}$. Nearly $33 \%$ had a family history of coronary artery disease in the study conducted among Pakistani medical students. ${ }^{13}$

In our study the prevalence of hypertension was $27.1 \%$. This is similar to the prevalence of hypertension (24.2\%) reported in a previous study conducted among medical students at Bareilly. ${ }^{12}$ Lower prevalence of high blood pressure (8.0\%) was reported among medical students of central India. ${ }^{14}$ Shaikh et al identified gaps in the knowledge regarding both modifiable and non-modifiable risk factors of hypertension among medical students from UAE. ${ }^{15}$ About one fourth of the students were found to be overweight and more than half had an increased waist hip ratio in the present study. Similar findings were observed among the students of Lahore medical and dental college where $20.5 \%$ were overweight and $6.2 \%$ were obese. $^{4}$

Fifteen percent of the female dental students of King Abdulaziz University, Saudi Arabia were overweight or obese. ${ }^{16}$ BMI analysis showed that among the dental students of Riyadh, 18.6\% were overweight and $7.8 \%$ were obese. ${ }^{17}$ Increased BMI and waist hip ratio was found to be higher among the males in our study. Similar results were reported among medical students in Greece ${ }^{18}$ whereas in the study conducted in central India ${ }^{14}$ the prevalence of increased WHR was more among the female medical students. About 14.8\% were anemic in our study. Higher prevalence of anemia was found among medical students of Chhattisgarh (30.20\%)19 and Barabanki (32.0\%).5 Anemia was significantly higher among the females in our study. Similar trends were reported in the studies conducted in Chhattisgarh and Barabanki. ${ }^{19,5}$

The awareness regarding obesity, hypertension and anemia should be improved among the dental students. Early identification of Hypertension, obesity and anemia and their modification among these future doctors is required.

\section{REFERENCES:}

1. World Health Organization. Report on preventing chronic diseases: A vital investment. World Health Organization, 2005.

2. Rustagi N, Taneja DK, Mishra P, Ingle GK. Cardiovascular Risk Behavior among Students of a Medical College in Delhi. Indian J Community Med. 2011; 36(1): 51-53.

3. Hingorjo MR, Syed S, Qureshi MA. Overweight and obesity in students of a Dental College of Karachi: lifestyle influence and measurement by an appropriate anthropometric index. JPMA 2009; 59: 528.

4. Zafar S, Haque IU, Butt AR, Mirza HG, Shafiq F, Rehman AU et al. Relationship of body mass index and waist to hip ratio measurement with hypertension in young adult medical students. Pak J Med Sci 2007; 23(4): 574-579

5. Bano R, Mishra A, Ahmad N. Study of Nutritional Anemia In the Medical Students Of Hind Institute Of Medical Sciences, Barabanki. JARBS. 2012; 4(2): 101-103.

6. Hypertension control. Technical Report Series: World Health Organization; 1996. Report No.: 862.

7. Snehalatha $\mathrm{C}$, Viswanathan V, Ramachandran A. Cutoff values for normal anthropometric variables in Asian Indian adults. Diabetes Care. 2003; 26(5): 1380-4. 
8. Steering Committee of the WHO Western Pacific Region, IASO \& IOTF. The Asia-Pacific perspective: Redefining obesity and its treatment. Australia: 2000.

9. Webb G. Nutrition: A health promotion approach. 2002: 186.

10. WHO. Tech. Rep. Ser. No. 405; 1968.

11. Sood S.K. U Rusia, WHO guidline for anaemia, Ann of Nat Acad of Med Sci, India; 22(4): 235, 1986.

12. Mahmood SE, Ansari SH. Lifestyle disease risk factors among first year medical students in Bareilly. NJIRM 2013; Vol. 4(2): 50-54.

13. Aslam F, Mahmud H, Waheed A. Cardiovascular health--behaviour of medical students in Karachi J Pak Med Assoc. 2004; 54(9): 492-5.

14. Jain J, Mathur H, Apte S, Sinha U, Agarwal K, Chanchlani R. Prevalence of Prehypertension and Hypertension and its Correlation with Anthropometric Measurements in Medical Students of Central India. Journal of Evolution of Medical and Dental Sciences 2014; 3(10): 2429-33.

15. . Shaikh RB, Mathew E, Sreedharan J, Muttappallymyalil J, Sharbatti SA, Basha SA. Knowledge regarding risk factors of hypertension among entry year students of a medical university. J Family Community Med. 2011; 18(3): 124-129.

16. Al-Zahrani MS. Obesity and physical inactivity among female dental students. Al-Qura Univ. Medical J. 2010; (1)1: 12-21.

17. Shereen MS, Al-Maflehi N, Husaini NA, Selga RA, Jaber TA. Preference of food intake among dental students in relation to exercise and body mass index: A cross-sectional study. International Food Research Journal 2014; 21(2): 685-691.

18. Bertsias G, Mammas I, Linardakis M, Kafatos A. Overweight and obesity in relation to cardiovascular disease risk factors among medical students in Crete, Greece. BMC Public Health 2003; $3: 3$.

19. Pandey S, Singh A. A cross sectional study of nutritional anemia among medical students in a medical college, at Bilaspur, Chhattisgarh. National Journal of Medical Research 2013; 3(2); 143-146.

\section{AUTHORS:}

1. Qazi Rais Ahmed

2. Rajesh Kumar Seth

3. Syed Esam Mahmood.

\section{PARTICULARS OF CONTRIBUTORS:}

1. Associate Professor, Department of Physiology, Rohikhand Medical College and Hospital, Bareilly, U. P. India.

2. Assistant Professor, Department of Community Medicine, Rohikhand Medical College and Hospital, Bareilly, U. P. India.

3. Ex-Assistant Professor, Department of Community Medicine, Rohikhand Medical College and Hospital, Bareilly, U. P. India.

\section{NAME ADDRESS EMAIL ID OF THE CORRESPONDING AUTHOR: \\ Dr. Syed Esam Mahmood, C5, Ahliyabainagar, Kalyanpur, Lucknow - 226022, U. P. Email: semahmood@gmail.com}

Date of Submission: 28/08/2014. Date of Peer Review: 29/08/2014. Date of Acceptance: 09/09/2014. Date of Publishing: 15/09/2014. 